\title{
The lexical mapping of politeness in British English and Japanese
}

BARBARA PIZZICONI

\section{Abstract}

This paper proposes the study of British English and Japanese conceptualizations of politeness by means of a measurement of the semantic domains which arguably constrain the expressive choices of speakers of these languages. Such measurement involves eliciting native speakers' similarity judgements of pairs of lexical items (metapragmatic judgements of attitudes and behaviours such as 'polite', 'kind' or 'considerate'), mapping them onto bi-dimensional spaces, and interpreting the nature of the two principal dimensions held to contribute to the distribution of the items. These findings are compared with the results of previous works on this topic. Moreover, the paper discusses issues of methodology in the treatment of data relevant to analyses that attempt to link linguistic and cultural facts, and individual and cultural representations.

Keywords: cultural universals, relativity, Japanese, British English, semantic structure, multidimensional scaling

\section{Defining politeness}

Recent important critiques of politeness research (see Eelen 2001, Watts 2003, and Pizziconi 2006a for a concise review) have hinged on a serious philosophical and methodological issue - the progressive 'scientific' abstraction of the notion of 'politeness' carried out in pragmatic approaches - that has perhaps unwittingly removed the study of politeness from the realm of social interaction to which it more properly belongs. The attempt to distil global principles out of instances of language use, goes the argument, brings the lens of the analyst away from the nittygritty of social values, judgements and manipulations, in other words the linguistic ideologies that polite language subsumes, by which it is 
informed, and which also give politeness phenomena distinctive, culturally specific, or context specific flavours.

I largely concur with this criticism and with the claim that the ideological' dimension of politeness phenomena needs to be brought into relief. At the same time however I wish to argue that 'situated' meanings can only be mobilized (recognized, strategically utilized, modified) in relation to some broad, culturally shared, and therefore not necessarily context-specific, meanings whose investigation can enrich our understanding of language in context, together with the contribution of other various socioculturally-oriented approaches.

Although pragmatics should by definition concern itself with the relation between signs and contexts of use, the recent history of politeness studies has shown that it is possible to adopt a reductionist approach that neglects the interactionally idiosyncratic purposes that the use of those signs is meant to achieve, given the various possible interpretations of what the notion of 'context' should refer to (for example abstract and absolute, as opposed to situated and emerging notions of power, distance, etc; cf. Goodwin and Duranti 1992). Various strands of semantics are likely to have similar merits and demerits. However the interplay of universal and culture-specific aspects in language cognition is not an issue that the field can afford to ignore. It is undeniable that human beings have developed concepts and categories, and often even institutional structures, which can be recognized across languages and cultures. It is also undeniable that, as social artefacts, such meanings and structures are subject to infinite local variation.

This paper approaches the study of politeness from the viewpoint of the lexicon - more precisely, the domain of terms used as evaluative qualifiers of behaviours and attitudes commonly associated with politeness (metapragmatic judgements such as 'courteous', 'considerate' or 'friendly'). Lexicon is imbued with the ethos of a language; it is a foundational component, to use a Whorfian idiom, of "fashions of speaking", as much as grammatical or discoursal features. But clearly lexicon also carries traces of universally common forces on human processing, such as the effects of bodily experience on the categorization of reality (cf. for example Hiraga 1999 on the role of spatial metaphors in politeness). Both aspects are important to investigations of politeness.

The approach described in this study does not intend to capture the sophisticated nuances of politeness in interactional 'games', but provides us with an illustration of culturally significant meanings: concepts and distinctions embedded in the language. It can outline a platform, a starting point, for a more integrated, complex type of analysis that must eventually involve the observation of the personal, interactional and social purposes for which meanings are seconded. Semantic analyses of the 
type I will present here take us only half the way. Socioculturally informed approaches must complete the task.

Criticism of previously dominant accounts of Politeness that defined it as a pancultural phenomenon of human interaction (most typically Brown and Levinson's model of (1987 [1978]), has pointed to the lack of fit to accounts of this or that linguistic or cultural practice, or to emically relevant regulating principles (e. g., the user's concerns with individualistic or collectivistic notions of self, or volitionally-based vs. social indexing-based principles; Ide 1989). Comparative studies attempt to extract the features of such specific instantiations. However, such studies are challenged by the often undeclared but inevitable fundamental question of whether the objects of analysis are indeed comparable entities (see for example the methodological solution of a 'natural metalanguage' proposed by Wierzbicka 1992). Moreover, once the significant lexical labels that are vehicles of politeness meanings in a certain community have been elicited one way or another, the methodological problem remains of the status of those meanings in the context of worldviews, communicative styles, language ideologies, and beyond to cultural preferences, etc. The task of describing a world through the words that inhabit it without recourse to stereotypical, impressionistic, subjective or, worse, ethnocentric arguments commonly used in lay discourse is no mean feat. Which structures count as evidence that culture $\mathrm{X}$ is individualistic? Which idioms demonstrate that culture $\mathrm{Y}$ is particularly sensitive to social hierarchies? Are structures, idioms or discourse patterns unmediated linguistic tokens of culture-wide worldviews?

The question is deceiving, insofar as worldviews belong to individuals and not cultures. However, language users of all times and of all linguistic progenies have at times deplored, other times celebrated, the expressive possibilities offered by one language that another did not contemplate, or the repertoire afforded by one language, stigmatized by another; hence the possible landscapes for such worldviews must pertain to languages as well. Languages enable or constrain worldviews, by making them objectifiable, and they reveal the "approved" conception of the world of the respective linguistic groups (Schutz 1973: 349).

In a similar way, politeness as a linguistic phenomenon that regulates social interaction is necessarily constrained by specific 'ways of experiencing' polite interaction and hence by the conceptual 'grid of reference' that conventions of (verbal) polite interaction in that language and culture have constructed. The nature of a lexical domain of politeness-related terms is defined by its overall scope and by salient conceptual distinctions that determine the terms' internal organization. The latter lie beyond speakers' consciousness, but clearly participate in processes of social cognition. This study attempts to extract and isolate some of these 
conceptual criteria of semantic organization, and to provide empirical definitions of the principles likely to be main contributors to the domain's 'flavour'. These principles, I maintain, afford us a platform for a description of the conceptual topography responsible for language specific views of politeness, and suitable for cross-linguistic comparison.

Before I move on to illustrate my study, and by way of an introduction to the epistemological challenge posed by the questions of conceptual equivalence and the extrapolation of cultural features from linguistic facts, I will first briefly present some previous works relevant to these questions.

\section{Previous studies on politeness-related lexical domains in Japanese and English ${ }^{1}$}

The following two studies assume a lack of cross-linguistic conceptual equivalence between the different sets of politeness-related terms, and discuss the significance of those terms and meanings in the context of the cultures observed. However, they explore the nature of such disparity by adopting different methodologies, and, despite some similarities, they also seem to produce different generalizations.

\subsection{Obana and Tomoda 1994}

Obana and Tomoda (1994) explore similarities and differences in Japanese and Australian English politeness terms with the cautious disclaimer that "culture-laden terms in one language cannot have isomorphic equivalents in another language" (1994: 37). They set out to investigate the matter by means of spontaneous interviews with 7 native speakers of English and 5 of Japanese; they prompted the conversations by asking the informants to recall an experience that "involved a rude or impolite statement, their reason to judge it as such, and then their interpretation of politeness". They then let their informants talk freely as long as they "could obtain from them the terms they thought were indicative of politeness" (1994: 39). The resulting terms are as follows:

Australian English: friendly, kind, approachable, considerate, wellmannered, humble, appropriate use of language, respect, modest, attentive, indirect

Japanese: reigitadashii, teineina, keigo, hikaeme, wakimaeru, enryo, joogekankei, tachiba (well-mannered, polite, honorifics, discrete, discerning, restraint, vertical relations, position, $b p)^{2}$.

They then proceeded to categorize the group of terms so elicited into a number of sub-groups, four for English and two for Japanese: 
a) ["warmly welcoming the interlocutor"] friendly, approachable, kind, attentive.

b) ["the speaker's concern for the interlocutor's wants and needs"] respect, consideration

c) ["differentiation of terms to be used in different social contexts"] appropriate use of language

d) ["non-imposing, non threatening statement toward interlocutor"] modest, indirect, humble

a') [wakimae: "discernment" (Ide 1989), or "recognition of one's social standpoint in relation to the other"] enryo (to be reserved), hikaeme (to be modest)

b') [keigo: "the usage of a particular type of language which expresses recognition of a certain relationship between the interactants"] enryo (to be reserved), hikaeme (to be modest) ${ }^{3}$, tachiba (bp, position), joogekankei (bp, hierarchical relationship)

Obana and Tomoda note the absence of equivalents in the Japanese language of the English terms "friendliness, consideration, attentive, approachable, kind" (1994: 47) but note the presence of terms (teineina, reigitadashii) that are associated with keigo (the linguistic system of honorifics and polite expressions) as a whole and with "aloof interactions, concern for keeping public face, and formal settings". This leads them to conclude that: "[s]ketching by this rule of thumb, politeness in English language is often associated with barrier-breaking features whereas in Japanese language, politeness initially sets up a social barrier" (1994: 46). They find this consistent with the different principles regulating the two societies: "individualism in Western society and amae (dependence, $\left.\mathrm{bp}^{4}\right)$ in Japanese society".

\subsection{Ide, S., B. Hill, Y. Cames, T. Ogino, and A. Kawasaki, 1992}

Ide et al. (1992) (also summarized in Ide and Yoshida 1999) similarly question the assumption of equivalence in key terms of politeness and set out to explore the concepts that "lie in the minds of native speakers" (1992: 282) of American English and Japanese. Their questionnaire asks subjects to examine a number of scenarios displaying the performance of various alternative (verbal and non verbal) behaviours (an ingenious method, as controlling the scenario allows the researcher to control the 'cognitive frame' activated). Subjects then assess each behaviour based on the lists of qualifying adjectives established by the researcher and quoted below. Because both "situations and adjectives were selected for cross-cultural comparability", and were translated from one language 
to the other, the Japanese and English terms are posited to be formal equivalents, and the purpose of the questionnaire is to test their functional equivalence.

American English: polite, respectful, considerate, friendly, pleasant, casual, appropriate, offensive, conceited, rude

Japanese: teineina, keii no aru, omoiyari no aru, shitashigena, kanji yoi, kidoranai, tekisetsuna, kanjoo wo kizu tsukeru, unuboreteiru, bureina

Subjects indicate with "yes, no, n/a" whether the adjectives "represented their own feelings if the words/actions had been directed toward them" (Ide et al. 1992: 283).

The study employs a multivariate analysis of the adjectives that looks at the correlation of the 'yes' and 'no' answers for each adjective with the respective scenarios. These correlations are then plotted on a bidimensional space, which shows the "degree of similarity of the ten adjectives as calculated from response data" (Ide et al. 1992: 284). The two axes of the plot are not labelled, but the data seem to indicate that while the American data are 'one-dimensional' (the first axis accounts for $92.3 \%$ of the data and the second for only $3.3 \%$ ) the Japanese data are 'two-dimensional' ( $75.5 \%$ and $13.4 \%$ ); an issue I will return to when presenting my own study. The particular arrangement of adjectives on the bi-dimensional tables lead the authors to conclude, among other things, that the judgments of English speakers were relatively homogenous whereas for Japanese speakers a fundamental distinction applies: that between a dimension including almost all the adjectives on one side, and a dimension of 'friendliness' ('friendly/non friendly') on the other, judged to be qualitatively different.

The relation of the various adjectives to the basic terms 'polite' and 'teineina' is also interesting: whereas the two corresponding terms 'respectful' and 'keii no aru' appear to correlate highly with the basic terms, and indeed to be on top of the list of correlations, things are much less clear from the second position downwards. In particular, the authors note that correlating with teineina is the adjective 'tekisetsuna' ('appropriate'), which they link to the Japanese orientation to 'discernment' or wakimae - a term which has now become common currency in politeness studies (Ide 1989; cf. Cook 2005 for a constructivist critique). In contrast, English 'polite' seems to correlate highly with 'considerate', which the authors take to instantiate an orientation to 'volitional' behaviour which "is careful not to hurt or inconvenience others, or has regard for another's feeling, circumstances, etc." (Ide et al. 1992: 290). 


\subsection{Evaluation}

The studies discussed above look at different varieties of English - Australian and American - and hence no valid comparison of these is technically possible. But their observations on the Japanese repertoires, and about how cultural orientations justify and/or are explained by such repertoires, exemplify relevant methodological issues.

Two different eliciting techniques were employed: open interviews and close-ended questionnaires. Only the first study, Obana and Tomoda's, elicits authentic user data (though 'adjusted' by the researcher in the second phase of the study): this provides useful information about the scope of the repertoires. In the second study, Ide et al.'s, the data are pre-selected or 'filtered' by the researchers. The second study however, subjects the researcher's pre-selected data to native's judgements - this means that while no significant conclusions can be drawn on the nature of the repertoire, the internal correlations identified within the repertoire tap into user competence, and hence constitute first-order data.

Despite these methodological differences there are some interesting convergences in the Japanese data and these are worth summarizing for the purpose of comparison with my study. The term teineina (politerespectful, bp) is noted for its association with reigitadashii (polite/wellmannered) and keigo (honorifics) or keii no aru (showing respect), all emphasizing conventional notions of politeness as etiquette. As for the relation of the vocabulary of politeness with more general cultural features one could speculate, though this is a further unempirical interpretive act, that when Obana and Tomoda define Japanese politeness as a device setting up a sort of 'barrier' between participants, they are hinting at the pressure to observe social structures, hierarchies, ranking, that Ide et al. refer to with the term wakimae. This underscores a functional difference of politeness in the two languages: the "barrier" that Japanese politeness sets up is said to be overcome in English politeness; Ide et al.'s more cautious observation stops at noting that the qualification of friendly is likely to correlate with that of polite in English but not in Japanese, where in fact it seems to be pretty much in contrast with it.

One of the clear challenges for any study of politeness is the leap between the analysis of first order data and a theorization of social and cultural orientations. Are sets of elicited terms unmediated devices utilized in order to "create social barriers", and/or indicators of existential individualism? What status can the judgement of terms that do not derive from culture-internal definitions be assigned? Which criteria can a researcher employ to draw the line between the necessary and sufficient sets of terms that justify, for example, the claim that the Japanese society is based on dependence (amae)? My feeling is that any such claims are 
likely to be contested in local contexts of use for at least two reasons: first of all, the unmediated and deterministic link established between linguistic and cultural facts, as well as the lack of a clear methodology to capture and explain the relevant mechanisms (social, psychological concerns) that generate and organize such mental representations (the lexical items) in the first place (Obana and Tomoda); and secondly, the imposition of the analyst's demarcation of the field of enquiry (i. e., the use of non-emic definitions, like the translated terms in Ide et al.).

The other big challenge is where to locate the role of culture in individual behaviour. Although clearly there is no straightforward threshold between cultural and individual worldviews, in the absence of an empirical methodology to corroborate these notions, we must produce some sort of working definition, or any claims made at a global, 'macro-level' are likely to be (and are) contested at the 'micro-level' of local experiences.

\section{Background to the present study}

\subsection{Lexicon and cognition}

The fundamental view of lexicon that inspires this paper is, in line with a rejection of objectivist semantics and positivist linguistics, that there is no reality other than the one experienced through language and hence that there is no immanent cognitive dimension that can be 'discovered' beyond language; that language is not an intra-organic, but an interorganic achievement and hence the result of mutual validation and social practices; and that language does not mirror but instead shapes reality (Hasan 1996; Bourdieu, 1991).

This view is ever more relevant when the analyst is confronted with 'cultural artefacts', or terms which involve a moral judgement, like the ones in the proximity of the notion of politeness. The nature of the lexicon affects the way discourse is organized, it concurs in the formation of linguistic ideologies, and has a considerable effect on self- and otherconstrual (see, for example, Pizziconi 2006b for a case dealing with Japanese acquisition). This position is summed up in Hasan's remark that rejects the dichotomy between form and content: "different ways of saying are different ways of meaning ... How we say is indicative of how we mean. And a culture develops characteristic ways of meaning. These ways of meaning, in their totality, are specific to that culture; they constitute its semiotic style" (1996: 191). Thus the study of a language's semantic resources is likely to say something interesting about the cultural concerns of the respective communities.

Such cultural semiotic style is not a static or monolithic notion; it can be, and is of course, contested and challenged, but such challenges 
presuppose that individuals are conversant with the 'rules of the game'. Novel uses of a term, for example, are never totally foreign to the original conventions of usage in that system, but rather derive from progressive and contiguous, if unpredictable and creative, manipulations. It is for this reason that in comparing semantic domains and attempting generalizations from these to cultural facts, systemic features rather than individual terms (and - more obviously - collective representations rather than individual representations), must be observed.

It is an established structuralist principle that meanings cannot be defined in isolation, but only make sense in relation to the network of other meanings with which they can be associated. In a discussion of the 'dictionary' of politeness, only once we situate terms like "polite", "respectful", "teineina", "kenson", etc. within the larger set of politenessrelated terms with which they are semantically related, with which they contrast, or with which they can co-occur, can we say something about the value of each term. Yet analyses of repertoires are often carried out as random juxtapositions of lists of items and generalizations drawn directly from them. What is needed instead is a rigorous and empirically grounded method to describe what are in fact coherent and structured conceptual fields. This study proposes a method for describing such structured representations and for foregrounding some dominant principles of their organization that maximizes users' input and interpretation and minimizes those of the analyst. This approach produces generalizations valid at the level of the system, which can then be globally compared with other systems. The advantage of this approach is that it produces an empirically derived mediating plane from which hypotheses can be made on language's relation to culture, and on how other mediating planes compare.

\subsection{Systemic properties and variation}

While universal aspects of politeness can be identified at the level of general biological or socio-psychological drives ('cooperative' vs. 'distancing' drives, House 2005: 17; 'connectedness vs. separatedness', Arundale 2006: 203) in socially situated contexts, variation in the way such drives are instantiated is the rule rather than exception. Cross-cultural variation is well documented, but culture-internal variation is no less important. One just needs to think of the stylistic variants of sociolects (be that age-, gender-, or class-based groups, etc.) to see how problematic culture-wide generalizations can be; since notions of politeness impinge on issues of morality and affect, we would expect them to be subject to a considerable degree of variation. This means that individuals in one community of practice may associate the notion of politeness mostly 
with friendliness, but those in another with conceitedness. In the domain of lexicon, this variability can be observed in the different associations that individuals would produce with some descriptive terms used as prompts. Such variable connotations of lexicon develop in the course of an individual's exposure to determined social contexts and communities (and their accompanying ideologies), and are moderated by that individual's personal set of beliefs and moral values (and the attempts to make reality coherent with an internal ideological take). But communities of practice themselves are not airtight or secluded units operating in isolation and in parallel fashion. One is likely to interact across various communities and be exposed to variable practices, and such varied exposure, subjective as it may be, generates a sort of statistical computation of how meanings are used in a variety of context. In other words, subjective variability is constrained by the regularities perceived in social encounters - lest one renounces mutual intelligibility ${ }^{6}$ (Terkourafi 2005 makes a similar point with regards to how norms and ways of enhancing/ threatening face are born and appropriated; House 2005: 16-17). This is consistent with Sperber's (1996: 57) definition of cultural representations as mental representations that are widely distributed and longlasting. The 'cultural' status of a linguistic object (as well as a cultural practice) is a function of that object's stability, arguably presupposing recognizability, transmissibility, and applicability to socially significant contexts of use.

While accepting that linguistic structure is not categorical, that variation is inherent in language use and that the notion of 'average use' is an abstraction which may fail to represent the real behaviour of any one user (see Eelen 2001: 216 for a similar argument with regards to cultural norms, and a point I will return to below), I am postulating that considerable regularities can be observed in the representation of meanings - note the following crucial caveat - only when they are considered as prototypical (or stereotypical) meanings ${ }^{7}$ rather than when observed in particular contexts of use, associated with particular frames, or particular metapragmatic intentions (Schutz 1973: 323 iv., 350). A parallel to this distinction is that found between the so-called 'semantic memory' and 'episodic memory' (Tulving 1972). Whereas the latter is constituted by 'one shot' experiences, the former is a generalized (hence decontextualized) knowledge derived from the sum of subsequent exposures to experience. On encountering one occurrence of the term 'polite' used to evaluate a person's behaviour, a gesture or an attitude, a trace is left of that episode. Subsequent experiences of occurrences of the same term add up to constitute one's semantic memory of the overall coverage of that term. 
The picture of the repertoires that this study offers (which is based on a computation of the average of user reports about degrees of similarities perceived between pairs of items) aims to depict an abstract (meta)representation of the systemic properties of the lexical field of politenessrelated terms. No statements will be made here about how such repertoires are deployed in situated contexts.

The repertoires described are not exhaustive - their scope would be unmanageable with the method adopted - but I will illustrate how we can describe the internal organization of a small sub-set of terms in these repertoires, and produce some interpretive generalizations about the principles governing such organization. This provides an illustration of the lexicalized conceptual landscape and the 'stock' of expressive possibilities available to individual language users (cf. Slobin 1996: 75) and further, suggests ways to characterize the inbuilt 'ethos' of a specific semantic domain.

\subsection{Semantic domain: A definition}

This study attempts a characterization of the semantic structure of politeness-related terms in English and Japanese. The goal is to establish a map of the semantic domain instantiated by (some) terms relating to the conceptual categories of politeness and teineisa (see the section on the methodology for the reasons of the choice of these two terms). In order to describe the semantic domain (the realm of concepts) we start from a description of lexical fields (the realm of words). Once the lexical items have been plotted onto bi-dimensional maps, an interpretation of the criteria that arguably govern their distribution is proposed. This is an explorative technique: such criteria are not defined a priori, but are hypothesized as the optimum heuristics for the configurations obtained (Schutz 1973: 58-59).

The definition of semantic domain, as well as the methodology adopted in this study, follows Romney et al. 1996, Romney et al. 1997, Romney and Moore 1998, Moore et al. 1999, Romney et al. 2000, and Rusch 2004. Romney et al. (1996) propose that "the structure of the semantic domain is defined as the arrangement of the terms relative to each other as represented in some metric system such as Euclidean space and described in terms of a set of interpoint distances obtained by scaling judged similarity data. [...]. An important assumption is that the resulting spatial cognitive representation is, in some sense, isomorphic with what is in the mind of the subject" (1996: 4699) ${ }^{8}$. Importantly, in the presence of empirical evidence that responses do concentrate around similar ratings we also assume that the resulting configuration may be 
seen as reflecting a reliable approximation of a collective cultural representation, which we derive from individual representations.

It is important to remember here that while individual semantic maps may be taken to reflect internal cognitive representations (Romney and Moore 1998: 322), mean collective representations are external, theoretical abstractions. Individuals are likely to produce personal mappings which resemble the pattern overall (due to commonalities in social experience) but may differ in the detail (due to differences in such experience). Culture is viewed as deriving from the shared (stable, pervasive) aspects of such individual representations. A strongly diverging representation (e. g., radical disagreement in the way a term is understood, or defined) is also possible, but it was not observed in this study.

\subsection{Methodology}

In order to obtain the list of terms for the similarity rating in an empirical fashion (and avoid the pitfalls of translations, as pointed out in Osgood et al. 1975: 66), a total of 27 native Japanese speakers and 11 British English speakers were asked to produce unlimited lists of associative terms ${ }^{9}$ from the following prompts: polite for English, and a. teineina and b. keigo (honorifics, noun) for Japanese. The lists of associations thus derived were then used to generate cues for similarity ratings.

A first crucial caveat is that none of these prompts was assumed a priori to be central or basic in anyway to the category as a whole. They have been chosen for their generality and on the basis that they are common and frequently found in lay discourse. To be sure, polite is more frequently used than teinena; Japanese also commonly employs the term keigo (lit. honorific language) to index a type of deferential behaviour (poraitonesu or Taiguu Hyoogen - "considerate expressions" - being exclusive to scientific jargon). The reason for the choice of two terms in Japanese: 'teineina' and 'keigo' (as opposed to just 'polite' for English) is to do with the fact that in talks with Japanese speakers, keigo is the very 'key-word' which triggers immediate recognition when disambiguating the more vague term teineisa, which also refers to 'careful', 'meticulous' manners; this double choice was also justified by the fact that the terms keigo (honorifics), sonkeigo (deferential honorifics), kenjoogo (humble honorifics), teinego (polite or formal honorifics), or kotobazukai (manner of speech) invariably appeared in the associative terms generated from the prompt teineina, therefore indicating an exceptionally high degree of association. This suggests that, unlike in English, the very existence of a grammaticalized honorific system significantly affects the collective consciousness of this phenomenon: it makes it instantly recogniz- 
able, more iconic, and consequently, more readily associated with conventionalized or stereotypical images of polite behaviour.

The lists produced ranged from 3 to 46 terms per individual in Japanese, 5 to 16 terms per individual in English ${ }^{10}$. Note that this artificial elicitation is a rather decontextualized task, where 'decontextualized' refers to a setting in which no obviously recognizable conventional social activity is taking place, such as was the case with the request to "write a list, as long as you like, of terms you associate to the term 'polite". It may be that in producing such lists, informants mobilized specific, situated, scenarios (as was instead explicitly prescribed in the studies described above), but I would argue that these associations were more likely affected by idealized narratives of politeness ${ }^{11}$, triggering items that were easily available and frequently accessed (Osgood et al. 1975: 45).

In order to make the two lists internally consistent (and facilitate respondents' judgement of the similarity of paired terms), I then proceeded to select a) only the terms which could be used attributively and b) the top 10 entries in the two respective languages. Hence eliminated from the lists were nouns such as 'keigo', 'nihonjin' (= honorifics, Japanese person) or 'good manners'; formulas such as 'my apologies', 'thank you' or 'doozo', 'sumimasenga', 'doo itashimashite' (= please, pardon, don't mention it); and obvious opposites such as 'rude' or 'burei' (= impolite), as the position of these terms was held to be rather predictable ${ }^{12}$.

The sampling criterion generates a uniform list of terms that can be used as metapragmatic comments, i. e., evaluative qualifiers of polite behaviour or polite stances.

The resulting top ten terms are as follows ${ }^{13}$ :

English: polite, appropriate, nice, considerate, courteous, distant, kind, friendly, well-mannered, educated

Japanese: teineina (polite), reigitadashii (appropriate/well-mannered, lit. $=$ of correct manners), omoiyarinoaru (considerate), seijitsuna (sincere, decent), shinsetsuna (kind), kenkyona (modest, humble), joohinna (refined, genteel), herikudaru (humble), wakimaeru (discerning), enryogachina (reserved, modest)

Since the original set of items that produced the above two lists were generated by a relatively small number of speakers, the repertoires that they illustrate cannot necessarily be assumed to be shared by larger samples of population. However, note that the point of this analysis is not to compare entire repertoires (which, as open-ended sets constantly subject to re-elaboration, would be difficult to compare anyway), but to look for the underlying dimensions governing the similarity ratings be- 
tween pairs of items belonging to such sets - the point described in the next step of the procedure. The number of individuals tested on the similarity ratings is indeed much larger.

An additional problem rooted in the methodological procedure is the double arbitrary reduction of the sets to two ten-items lists, and to attributive terms. Although this does not solve the methodological issues mentioned in 2.3, it affords a minimal interference on the part of the analyst.

The ten terms so obtained were then paired and listed on the sides of a five-point Likert Scale, with 5 indicating strong, and 1 weak, similarity (Appendix 1). Respondents were asked to rate each of the 45 pairs and to provide personal information as to their gender, age group, and length of residence abroad ${ }^{15}$.

The questionnaire was then published in two formats: on a website hosted on the SOAS server, which allowed automatic submission, and as a word document, which could be completed either electronically and returned as attachment or printed out and filled in by hand. This was done in order to maximize distribution and to minimize the effects of computer accessibility. Respondents used all three forms of submission. A call for participants was posted to an initial circle of personal acquaintances (about 50 people) who were asked to circulate the call as widely as possible to other friends, acquaintances, relatives. This resulted in a total of 88 responses for English and 156 for Japanese, in the period between 22 July and 15 August 2005 (Appendix 2) ${ }^{16}$.

The results obtained were also compared for the three variables of gender, age and length of residence abroad. Surprisingly similar results were obtained in the male/female versions of both the English and the Japanese data sets. As for age and length of residence, some small differences were found only in English. At a first examination, it appears that the differences consist in small variations in the positions of individual items, while the clusters do not sensibly change in shape. For this reason, I will not discuss these variables in the present paper. I will however comment briefly on the results obtained for gender.

Testing the semantic mapping with gender as an independent variable showed very little effects on the configurations obtained, which indicates that the underlying, governing dimensions originally identified for the whole group are solid. Given the socio-cultural significance of politeness and its not-so-subtle interplay with the politics of gender, we would have expected some sort of detectable distinctiveness of gender-based groups. This study does not rule out that this may indeed be the case in situated contexts of use, but this result may be a reflection of the type of 'abstract' knowledge the test taps into, as discussed earlier. The dimensions iden- 
tified seem to be deep, latent and relatively homogenous frameworks of reference that are indeed shared across gender groups.

Average rating was used to carry out a correspondence analysis ${ }^{17}$ of the similarity ratings described in the previous section. This tells us how each of the terms in the two sets of ten correlate to each other in terms of some underlying dimensions. Such dimensions can be interpreted as criteria of semantic organization that govern lexical distribution.

Table 1 and Table 2 ('Summary of similarity rating by English/Japanese speakers', Appendix 3) show a standard deviation which suggests that a significant majority of responses clusters around the mean score. Variation in responses is sufficiently small for us to rely on the mean as a representative value of the respondent's semantic representation.

Because the data will be plotted on a bi-dimensional plane, only two out of the ten dimensions responsible for the configuration observed (which must be understood to be all at work at the same time) will be discussed $^{18}$. The first two dimensions account for $75 \%$ of the inertia ${ }^{19}$ in the English data, and for $72 \%$ of the Japanese data. Such cumulative percentage of inertia is a measure of the degree of interaction or "association" between each of the terms in the table ${ }^{20}$.

The method adopted is not particularly advantageous as a representation of individual meanings, of which it tells us nothing, but since the resulting representation is derived from similarity ratings, it does highlight meaningful clusters and underlying dimensions or principles of semantic organization; these would normally not be available or be perceived in isolation, but they exist as features or facets of language use. This approach extracts and isolates principles of semantic organization but they must be taken to operate at some unconscious level of lexical competence.

The perceptual map plots the entries based on their scores along the two dimensions, and illustrates not only their distribution and grouping, but also how strongly each of the terms contributes to the dimensions in question. This latter information is given by the distance of a term from zero, e. g., terms in the periphery of this map contribute to the dimension more than terms close to the centre.

\subsection{Analysis of the perceptual maps}

I will begin by making observations on the configuration of terms in the plotted maps, and then attempt to foreground the principles which may arguably account for such configuration. I will then propose a conjectural definition of the nature of the underlying dimensions regulating such distribution. 
Before proceeding with a detailed discussion of the mapping in the two semantic systems, I wish to draw the reader's attention to my observation that the two axes that govern the configuration appear to be qualitatively similar, although different in the order of importance. In both the English and Japanese mappings (figures 1 and 2 respectively), the principal dimension, which accounts for the highest proportion of variation in the data, is the horizontal axis, whereas the secondary dimension, which accounts for the second highest proportion of the variation, is the vertical axis. My interpretation is that the dimension that corresponds to the horizontal axis in the English mapping appears to represent a similar type of conceptual discrimination to that of the vertical axis in the Japanese mapping. Intuitively, this means that if one rotates the English mapping by $90^{\circ}$ anticlockwise, one obtains a graph that is similar to the Japanese mapping in terms of the cognitive principle by which the words are clustered. In the interpretation of the two mappings below, in order to focus our discussion on the mutual similarity of the two dimensions, the convention of interpreting the dimensions (or axes) in the order of their ability to account for higher variation is not followed.

\section{English}

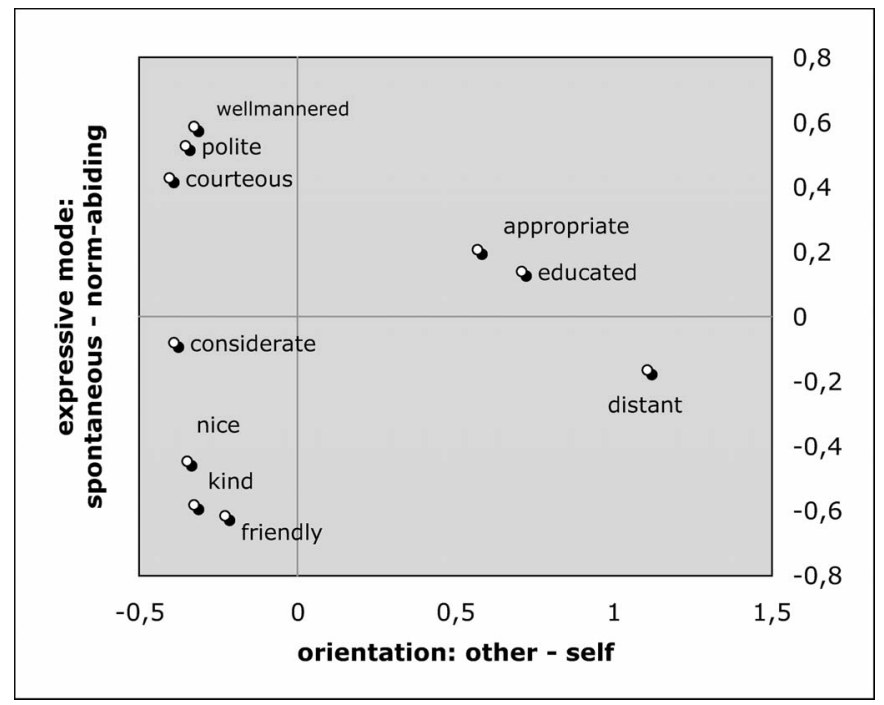

Figure 1. English perceptual map.

We can begin our analysis of the English perceptual map by noting a couple of clusters: 'polite'-'well-mannered'-'courteous' and 'nice'-'kind'- 
'friendly'. We interpret clusters as semantic adjacency, so we note that the two terms most strongly correlating with 'polite' have to do with relatively traditional conceptions of politeness as etiquette (courtly behaviour, manners), and that they are positioned a fair way apart from the second cluster. We also note that 'appropriate' and 'educated' are closely associated, and that 'distant' and 'considerate' are rather isolated.

Since all the terms elicited were derived by means of associative chains, they all have to be understood as bearing some sort of relevant relation to each other in the minds of the users. But the clustering itself helps with visualizing the different nature of these associations (independently from how we interpret it). Of course someone who is 'courteous' can theoretically also be 'friendly' but this grouping entails that items in the same clusters are perceived to be more strongly, or easily, associated with each other than with items in another cluster. I would also venture to say that exploring these connections as suggesting likely co-occurrence patterns may yield interesting implications for the analysis of the argumentative purposes that these terms may serve in situated contexts.

Now we come to the task of interpreting the nature of the two underlying dimensions that govern such configuration. I propose that they could be construed as follows.

\section{HORIZONTAL AXIS - Orientation: self vs. other; low vs. high affect}

If we look at the terms on our map most further away from the zero value of the horizontal axis (i.e., those which contribute most to this dimension), we note first of all the strong influence of the three terms on the right, and in particular of 'distance' 21 . In contrast, we notice that the two clusters 'well-mannered'-'polite'-'courteous' and 'nice'-'kind''friendly' are distinctly positioned on the left of the map.

This contrast can be described in terms of several traits characterizing the underlying dimension. Although one of the advantages of this analysis is the production of a minimal number of criteria to describe complex semantic configurations, the fact that a dimension can be described with more than one label is not necessarily problematic - especially if, as in this case, one characterization subsumes the other.

First of all, in some basic cognitive sense, this describes an orientation toward some object of consideration, ranging from an (interpersonal) 'outward' or 'positive' consideration of others, on the left, to an (intrapersonal) 'inward' type of consideration, on the right. Here, I use the term 'consideration' not in the sense of 'respect', but in the more general, cognitive sense of 'locus of attention' ${ }^{22}$. Thus being 'considerate' or 
'courteous' implies a 'gaze' toward others, not explicitly referenced by 'educated' nor 'distant'.

But the 'orientational' contrast is subsumed by another: a contrast on the affective level. It can be described in terms of attitudinal states characterized by a certain degree of outward solicitude, on the left, and more aloof, or more 'detached' attitudes on the right. In other words, this configuration highlights various degrees of emotional engagement or 'arousal' (involved vs. uninvolved), or various degrees of demonstrativeness. The parallel with the human relational modes of connection and separation, approach and avoidance is, I think, not too far-fetched.

The position of 'appropriate' and 'educated' not surprisingly contributes strongly to this dimension as a 'low affect' feature of politeness; this latter term is problematic when affect is at issue (which possibly explains the fortune of the term 'appropriateness' as a scientific byword for politeness in recent accounts). The relatively 'ordinary' term 'nice' on the contrary seems to have an important role in the indexing of 'high affect'.

\section{VERTICAL AXIS - Expressive mode: norm-abiding vs. spontaneous}

When we look at the vertical axis, we note the strong contribution of 'well-mannered'-'polite'-'courteous' at the top positive values (and the weaker contribution of the cluster 'appropriate'-'educated'), of 'nice''kind'-'friendly' at the bottom negative values, and the intermediate positions of the remaining terms; they all contribute to this dimension proportionally to their distance from zero.

The basic distinction seems to hinge on that which obtains between traits that are associated with 'nurtured' attitudes and those associated with 'natural' attitudes. In this sense, we can see a parallel between different modes vis-à-vis social protocol: attitudes which index some kind of 'constructed', 'affected', or 'educated' regard for social manners at the top, and a more genuine, relaxed, or 'spontaneous' kindliness or sympathy at the bottom.

Therefore, contrasted with the more 'affective' dimension discussed above, this dimension could be characterized by a 'social indexing' overtone (fuzzy and overlapping as these categories may be). This discriminates between attitudes prototypically (but not exclusively) displayed among strangers or non-intimates (top) and intimates (bottom). Such a configuration can be illustrated in terms of different degrees of 'formality' that can be associated with the terms in the set, in the sense of the necessity of a certain regard for 'manners' in contexts of high-awareness of some sort of codified social norm, vs. attitudes that can occur independently from external protocols. 
Japanese

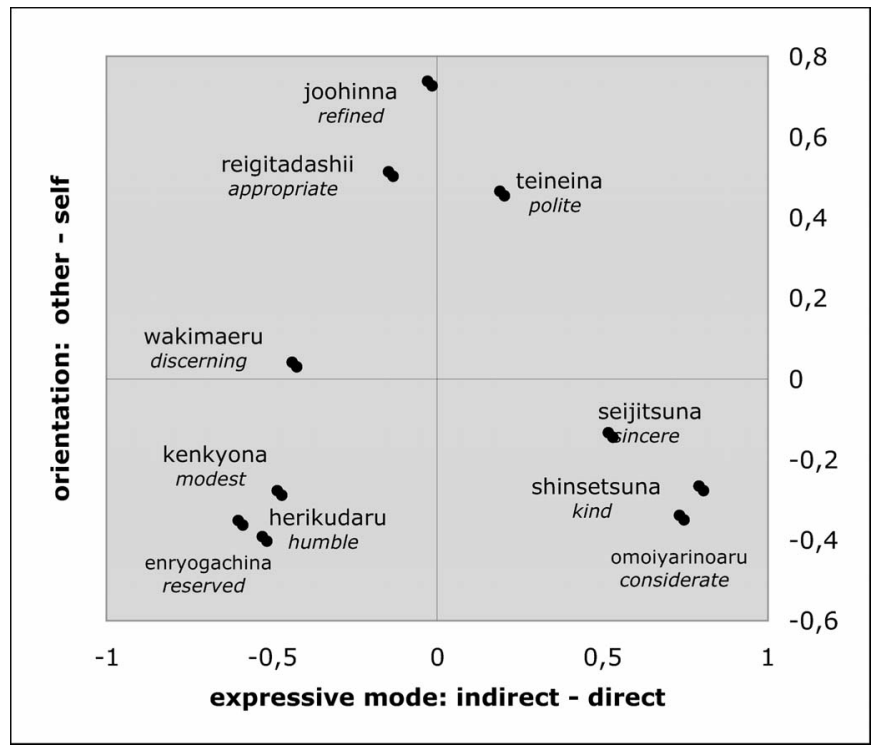

Figure 2. Japanese perceptual map.

Legenda: terms are glossed concisely in the map for easy reference to the English speaking readership, but see the following: teineina (polite), reigitadashii (appropriate/ well-mannered, lit. $=$ of correct manners), omoiyarinoaru (considerate), seijitsuna (sincere, decent), shinsetsuna (kind), kenkyona (modest, humble), joohinna (refined, genteel), herikudaru (humble), wakimaeru (discerning), enryogachina (reserved, modest).

Once again, we begin by observing the general outlook of the map. We have a clear cluster on the left: 'herikudaru'-'kenkyona'-'enryogachina', and a somewhat looser group of terms at the top: 'reigitadashii''joohinna'-teineina'. A third cluster can be observed on the right: 'seijitsuna'-shinsetsuna'-'omoiyari no aru', and we note that 'wakimaeru' is relatively independent and close to the zero value of the vertical axis.

As pointed out above, because the dimensions we identified in Japanese do not vary considerably with the standardization method employed ( $72 \%$ with row means vs. $75 \%$ with row and column means), we can speculate that the combination of factors contributing to these dimensions is more straightforward than in the English case.

\section{VERTICAL AXIS - Orientation: self vs. other; low vs. high affect}

The nature of this dimension seems similar to that of the horizontal dimension just described in English. It appears to highlight different 
types of cognitive orientation: the top group illustrates qualities which could be described as the payoff, for an individual, of being polite in interaction. Terms at the bottom index more directly other-concern.

Similarly to English, it also discriminates between weak (top) and strong (bottom) relational and affective engagement, depending on the predominantly 'inward' or 'outward' cognitive orientation. Thus while being 'joohinna' ('refined') or 'reigitadashii' (well-mannered) does not presuppose display of affect toward others, being 'enryogachina' ('modest, restrained') or having 'omoiyari' ('consideration, regard') presupposes the existence of such affective concern.

'Wakimaeru' (being able to adequately 'discriminate' social positioning) seems to have little relevance along this dimension, as can be expected of a fairly neutral term (and again, one which has now been adopted in the global literature on politeness; cf. Ide's (1989) use of the term wakimae to indicate Japanese speakers' propensity to prioritize considerations of status over 'volitional' strategies).

\section{HORIZONTAL AXIS - Expressive mode: direct vs. indirect}

Although this axis seems to index a 'mode' of the interaction, as we have seen for the vertical axis in English, this seems to be construed differently. Stronger than a characterization of operating modes that foreground an individual's positioning with regards to external norms (although it can be argued that this nevertheless applies, with terms on the left implying a stronger regard for some social convention - see herikudaru or wakimaeru - and terms on the right highlighting character-based traits) this configuration seems to evidence more clearly, or be enriched by a notion of, the 'path' of interpersonal demonstrativeness. While on one hand (the positive terms on the right) we have terms indexing explicit, overt, direct displaying some sort of regard for the other (also note seijitsuna $^{23}$ ), this is implicit, covert, indirect in the terms on the left. The term which is neutral to this dimension (as it refers to self orientation: 'joohinna') is close to zero. I would contend that the existence of a grammaticalized distinction in the Japanese honorific system (keigo), where sonkeigo (deferential forms) and kenjoogo (humble forms) refer respectively to deference displayed directly to the target by elevating it, or indirectly by 'lowering' the speaker, strongly supports the hypothesis that this is indeed a salient psychological and cultural distinction.

The location of 'wakimaeru' ('discriminating', 'discerning') on the left side of this dimension would seem to highlight that the focus of such 'discrimination' is on one's own position rather than that of other's (though of course this is a relative, interpersonal notion, that cannot do 
without the 'other' to define where 'self' stands). The raison d'etre of an act of wakimae is to avoid overstepping the boundaries of one's role; hence it is an inward act of modesty rather than one of assertion.

\subsection{Discussion}

This study has attempted to extrapolate significant frameworks of reference derived from users' data and makes the claim that these, and not individual items in the corpus, are indicative of salient dimensions of cultural conceptualizations, because these, as properties belonging to the collective rather than individual level, can provide the mediating link between linguistic and cultural facts. It has also applied a methodology so far implemented in studies of animal, kinship and emotion terms, to a description of collective representations of semantic networks in the field of politeness-related meanings.

The findings indicate, on the basis of the analysis of a sub-set of terms commonly associated with politeness in English and Japanese, that the two dominant criteria of organization of such lexical domains in both languages show both similarities and peculiarities.

The first similarity that can be observed is in the basic distinction between cognitive orientations: self-directed and other-directed attitudes, conveyed by comments that spotlight different aspects of being polite, based on the speakers' perception of the presence or absence of acts of attention for the other. Additionally, both in English and Japanese, the self-other orientation involves displays of different degrees of affective engagement, natural perhaps given the interactional nature of the phenomenon we are investigating.

Politeness can be variously construed based on the detectable direction of an individual's attention, and, associated with this, the presence or absence of a charged affect, or a sense of solicitousness and consideration. In English the scope of this category ranges from solicitous stances to more remote stances; in a moral sense, it can be noted that while all the terms relating to solicitousness have generally positive connotations, the one term in clear spatial opposition ('distant') is often connoted negatively. This may suggest that this term is somewhat peculiar in respect of the rest of the set, and therefore that it should have been eliminated from the sample (as more obvious opposites have, as noted above), but a further assessment demonstrated (see note 21) that this was not the case: this is a conclusion drawn on the basis of users' judgements and not an a priori interpretation.

In Japanese too, orientation seems to be a relevant dimension. Qualifiers discriminate between a high- and a low-awareness of the other, or traits that index intrapersonal or interpersonal attitudes. The lack of any 
negatively connoted term in this set should not be interpreted as a generally positive representation of polite attitudes, but at most as suggesting that negative associations are not conspicuous (lexicalized meanings: 'keien' [respectful distancing], 'reiguu' [cold treatment], 'tsumetai' [cold] appeared once in the initial sample, but are perhaps less immediately accessed. In terms of the range of terms elicited, those with explicit negative nuances are indeed hard to find; the same cannot be said for English - see note 10).

Demonstrating a polite attitude involves demonstrating active affective concern, but a low degree of such concern still has effects for the self (it is recognized as having 'meaning'), with both positive or negative nuances ${ }^{24}$. In both languages however, only a minority of terms carry the function of indexing self-oriented stances.

With regards to the mode of expression, that the two configurations can again be accounted for by means of the same frame of reference is noteworthy. Both languages can be said to distinguish between 'constructed', or 'cultivated', and 'innate', character-based, traits: speakers seem to distinguish 'nurture' and 'nature' in polite manifestations.

However this dimension shows, more importantly, a qualitative distinction: English seems to 'code' this in terms of the orientation to external protocol vs. spontaneous attitudes, Japanese seems to distinguish between modes of 'reservedness' (a form of 'withdrawal', but also an indirect mode of expression of deferential, respectful attitudes to a target) and modes of 'avance' (direct, outgoing expressive modes). Of course the concept of modesty is not an exclusive property of Japanese culture, but the concept is grammaticalized - as noted before - in Japanese, which may account for an enhanced sensitivity to this conceptual category. Grammaticalized taxonomic distinctions between deferential (direct) and humble (indirect) speech are likely to reinforce the creation and transmission of a conceptual category of modesty as processes of linguistic acquisition and, more generally, socialization practises arguably act as 'attuning' devices in the genesis of collective cognitive representations.

The contrasting position of the two related clusters in the English map can be associated to formal and informal behaviour (again, there is no need to assume that the terms index mutually exclusive stances, but just that each term is more commonly associated with a set than with another). Thus a ('unaffected' kind of) polite concern can be surely be displayed in informal contexts, but its 'label', in lay discourse, does not seem to be 'polite'. In scientific discourse, that politeness is not exclusively a feature of formal and high-protocol settings (as the maps seems to illustrate nicely) chimes with its conceptualization as more general 'politic behaviour' (Watts 1992), but the skewed position of the 'basic' 
term 'polite' on the map reveals its marked character in common parlance.

This is interestingly mirrored by the position of 'teinei', the other term I chose as a prompt for the first stage of this research, in the Japanese map. Its position is also peripheral, occupying a space which is characterized as relatively self-oriented, and a not even particularly 'expressive' mode. This seems to me to be of considerable importance: if it is 'politic behaviour' that we want to investigate, avoiding the use of these terms in eliciting data may be crucial, lest we artificially construct a cognitive frame which the users would not necessarily activate.

\section{Conclusions}

Much of what this study has shown resonates with the results of previous studies illustrated here - and others - but with important distinctions which derive, I think, from interpretive or methodological issues.

My study supports the association of Japanese culture with values such as 'modesty' and 'restraint' (mentioned in Obana and Tomoda's paper); an empirical grounding was found for the Japanese data. Had an English term like 'demure' (1 occurrence in my first sample) made it to the top ten terms selected for the similarity rating we may have had a different result, but English did not, even in the original sample, provide much evidence of a strong association of terms indexing 'modesty' with the original prompt 'polite' (which again exemplifies the need to problematize the prompt). Attitudes of 'restraint' can of course be codified in English as well, but nevertheless its lesser recognizability (due no doubt also to the lack of the metalanguage that Japanese possesses for its honorifics in lay usage as well) means that they are not very conspicuous in the polite domain examined. This would suggest that meanings that index the distinction between reserved and outgoing modes of polite interaction are more easily accessible for Japanese speakers than for English. Evidence that this is a salient distinction for Japanese was on the contrary rather convincing.

If we take the "barrier-breaking" function suggested by Obana and Tomoda (1994) for English politeness to index English's display of a concept of friendliness or informal consideration, then we can support their claim that such an element exists in English politeness (though not invariably connoting politeness); this also confirms Ide et al.'s (1992) very strong empirical result, that while 'friendliness' can be homologous with politeness in English, it is definitely not in Japanese.

My data also shows that a 'polished' self-presentation is a by-product of being polite in both languages and that it is a salient distinction. 
However, respect of vertical status (Obana and Tomoda's joogekankei) did not seem to emerge as a strong dimension in either of the two sets.

The results of my study are less 'stereotypical' than those of the studies reviewed, in that they seem to show that much is in common, and differences arise in the nuances of such otherwise analogous traits. They show that the resources - the conceptual constraints and possibilities - afforded to language users by their repertoires are fairly similar (in a basic sense of fundamental judgements about cognitive and affective distinctions that users can make), but they also offer different expressive possibilities (or they facilitate them) with regard to the preference for detail in 'informal', 'friendly' nuances of politeness in English, and 'reserved', 'modest' nuances in Japanese. From these different 'starting points', users set out in their infinite adaptations to situated realities. These interpretations now need further empirical testing.

Sperber's (1996) discussion of what he calls the "epidemiology of representation" provides some important pointers for any research on culture. With the epidemiological metaphor, he refers to the way in which many mental representations inhabit, like viruses, the human population. Some of these 'spread' from an individual to the public space (get communicated) and from the public space back into other individuals. Some spread more widely and become resistant (established) over many generations of the population (1996: 25). An epidemiological model tries to explain both the success and the modality of this spread.

The causal explanation of cultural facts amounts ... to a kind of epidemiology of representations. [This] will attempt to explain macro-phenomena as the cumulative effect of two types of micromechanisms: individual mechanisms that bring about the formation and transformation of mental representations, and inter-individual mechanisms that [...] bring about the transmission of representation".

(Sperber 1996: 49)

My study has delineated the cumulative effect of individual representations, but the parameters that explain this cumulative effect (be they affect, modesty or formality etc.) must make sense at the level of individual users and their environment, and it is at this local level that they need to be corroborated (Schutz 1973: 64). Social institutions are likely to be ecological reasons for certain cultural facts. Concepts of face may constitute psychological reasons. Such micro-mechanisms are already being addressed by a range of disciplines, but empirical data of the kind this study has proposed may provide useful pointers for such analysis. Further study is required of the mechanisms of transformation, i.e., how such socially relevant meanings are stabilized, modified, or abandoned. 


\section{Acknowledgements}

I would like to thank Satoshi Miyamura, Department of Economics at SOAS, University of London, who has acted as consultant and carried out the statistical analyses for this study, thus making it possible for me to explore concepts of politeness from this methodological perspective.

\section{Notes}

1. I have not included Patricia Wetzel (2001) in the overview of previous studies of politeness-related terms due its more restricted focus on 'etiquette', but I would like to refer the reader to this additional work.

Michael Haugh (2004) also offers a comparative study of conceptualizations of politeness, based on an examination of their definitions in various dictionaries. However, his discussion incorporates several other sources of definition, like those produced in theoretical formulations of recent pragmatics research, and therefore his conclusions are difficult to compare with those of the studies presented here. I have therefore decided not to include it in my review.

2. Translations are mine (and generic), as they were not translated in the original work.

3. The two terms enryo and hikaeme appear in both groups a' and b' in the original.

4. Amae refers to the sense of 'dependence' illustrated in Doi (1981).

5. A semiotic style assumes a congruence of verbal and non-verbal ways to mean. It can be considered as an overarching principle of organization which ensures the coherence of the system (a system created by humans to organize and communicate about reality). Although conflicting principles of organization can possibly be conceived we can still identify and talk of typical styles (as in Bakhtinian speech genres), or styles which are simply more frequently observed, or more stable, then others.

6. There is of course the chance that a speaker develops a highly idiosyncratic representation of the meaning of a term, based on exposure to a limited range of idiolects - this is indeed the default case for novices: children and language learners - but the same can be hypothesized for any other speaker. I am referring here to adult speakers with experience of a variety of interactional settings in networks of relationships from the close family circle to the school, professional circles, knowledge of the world through media etc.

7. A lot more should be said on the nature of such 'prototypical' meanings, i.e., whether these correspond to entities such as 'semantic primitives', or are akin to 'image schemas', etc., and about their psychological reality. The scope of this paper cannot accommodate an exhaustive discussion of this issue, so I will just use the temporary working definition of a 'second order' meaning generated by a crystallized idealization based on the traces of a chain of previous referencing events, contextually judged to display some perceivable similarity.

8. If this is correct, as the authors point out, such representation could potentially predict a number of cognitive processes such as categorical judgement time, completion of analogies, strength of semantic clustering in memory, etc. (Romney et al. 1996: 4699 and Romney and Moore 1998: 328). These have not been tested at present, but represent potential avenues of future research.

9. Additionally, the results of a similar task administered at SOAS in December 2004 were used for comparative purposes. 20 English native speakers were asked to "list three words [they] associate with 'polite". Two remarkable findings of this 
five-minute survey were that the whole list included a total of forty-two items, of which thirty-one generated 1 entry each, and that even the top four hits ('courtesy', 'thank you', 'manners', 'nice') generated only a handful of entries (respectively $4,4,3$, and 3 ). This suggests a rather loose or idiosyncratic relationship between these sets of terms; note however the limitation to produce only three items (a constraint that I did not add in the study described here). Apart from the prompt 'polite', 6 of the remaining 9 terms selected in the current study were however present, and most had more than one entry, in the December 2004 survey. 'Friendly', 'distant', and 'educated' did not appear, but the terms 'affection', 'strangers' and 'English upper class' were present and seem to echo those meanings.

I would like to take this opportunity to thank all those who participated in that first survey.

10. Japanese: teineisalteineina (polite); keigo/sonkeigolteineigolkenjoogo (honorifics/ deferent/polite/humble language); reigi (tadashisa) ([correct] manners); keii (wo motsu)/uyamau/tootobu/sonkei ([to have] respect/ to show respect/esteem/deference/regard); jogekankei no aru/meue, meshital toshiue, toshishita (vertical relations/superiors and subordinates/seniors and juniors); omoiyari kotobazukai, / hanashikata (speech manners); monogoshiltachiifurumai (demeanour/movements, manners); shikitar/kimari (customs, rules); shinsetsu (kind); yasashisa (gentleness); kyori (distance); keien (respectful distancing); shinso (intimate/non intimate); zootoo girei (gift giving etiquette); shinchoo (discretion); kichinto shitaltotonotta (proper, well-arranged); kizukailki o kubarulhairyo ga aru (attentions; pay regard; to be considerate); uchilsoto (in-out-groupness); mi o hikuku surulherikudarulkoshi ga hikui (prostrate/lower one self/to be humble); tsukau/manabu no ga muzukashii (difficult to use/learn); kazoku/hahaloya (family/mothers/parents); goyoo (errors); kenkyo (modest); joohin/hin ga arulhinsei/senreisa (sophisticated; genteel; refinement; polish); jigi (bow); seijitsu/seii ga aru (sincerity; acting in good faith/honourably); kiyoilseiketsu (pure/noble); richigi (honesty, faithfulness); sadoo (tea ceremony); kooshitsu (imperial household); wakimaerulba no fun'iki o yomulkejime (discern/'read' a situation/to make a distinction); shitsuke (discipline); shuukan/ dentoo (customs/tradition); kichoomenna(hito) (meticulous person); mendoo o miru (look after someone.); kashikomaru (to 'stand on ceremony'); majime (earnest, honest); junkatsuzai (lubricant); sensailkimekomakai (fine/delicate); utsukushii (beautiful); enryo (reserve); komakai (fine, detailed, particular); kicchirishita (tight); nihonjin (teki)/Nihongo (Japanese person, Japanese; Japan); wafuku (Japanese clothes); josei (women); burei (rude); tegamilkireina bunsholkisetsu no tegami (letter, fine writing; seasonal letters); aisatsu (greetings, formulas); nenrei (age); mendoo/mendokusai (hassle/troubling); reiguul tsumetai (cold treatment/cold).

English: acceptable; approachable; appropriate; bad-mannered; boorish; borgeois; caring; careful; calm; civil; civilised; charming; controlled; considerate; cold; cool; courteous; diplomatic; dignified; distant; demure; docile; educated; fair; friendly; formal; generous; good; gentlemen; gentle; gracious; indirect; happy; kind; mild-mannered; nice; not offensive; open; opaque; petty; precise; pleasant; reserved; respectful; responsive; proper; positive; quiet; respect; rude; selfless; sensitive; small; stiff; socially skilled; social ; soft; stuck-up; tactful; thoughtful; timid; uncouth; unctuous; Victorian; white; welcoming; well behaved; well mannered; well brought up; VERBS; apologize; beg pardon; greet; may; NOUNS; affection; child; china; courteousy [sic]; decorum; good manners; English upper class; etiquette; face ; freedom; honorific; language; lease; manners; maxim; obligation; others; respect; relationship; speech level; strangers; FORMULAS; my apologies; please ; sorry; thank you; will you/would you; could you. 
11. See note 7 .

12. The semantic mapping of a set of antonyms should also of course be empirically tested.

13. The translations offered here are $a d$ hoc and for the benefit of readers not familiar with Japanese. No claim is made as to their functional (or even semantic) equivalence.

14. The English translation does not fully convey the nuances of this term, associated with integrity, honesty, good faith, but also implying a strong component of genuine regard and concern for the other.

15. The choice of these particular demographic traits (and not, for example an index of linguistic proficiency in other languages) was based on the need to keep the questionnaire as concise as possible, and on the assumption that notions of politeness are affected by exposure to different cultural practices as much as linguistic proficiency in another language.

16. Although the social variables of age, gender and length of residence were examined in the questionnaire, the population may be characterized as a non-representative socioeconomic community because it self-selected partially on the basis of computer literacy (though some questionnaires, for example, were distributed by hand to elderly family members), and the contiguity to networks of academic acquaintance. The further the circle spread, the more variable the pool of testees is likely to have been, but socioeconomic class and educational background were not tested.

17. Correspondence analysis is a statistical method to account for the relationship between row and column variables by assigning optimal scores along underlying dimensions.

18. That multiple dimensions are responsible for the particular configuration of certain semantic representations (i. e., the perception of similarity) is consistent with the common characterization of politeness as a complex phenomenon of social cognition. This involves human beings' ability to create mental representations (subject to individual perceptions) of social facts (subject to collective constructions), that arguably involve universal as well as culture-specific aspects: social, moral, affective, and cognitive aspects, etc.

19. Inertia measures the strength of relationship within the data, and gives an indication of the degree to which the two dimensions are representative of the variation in the original data-set.

20. The standardization method that this paper describes is the standardization of the row means. Standardization of both rows and columns was also carried out. This did not affect the outlook of the clusters, which entails that the groupings are robust. However, the relationship between clusters, i. e., the underlying dimensions governing them, changed considerably in the case of English. The proportion of inertia accounted for by the first two dimensions (i. e., the degree to which they account for the relations between the items in the table) decreased, in English, to $64 \%$ (though it improved to $75 \%$ in Japanese). The former standardization method was therefore chosen for its better fit to the data. This means, however, that the 2 dimensions identified in English are less robust, and may not be a sufficient or exhaustive representation of the data set.

21. The extreme position of 'distant' suggests that as a sort of 'outlier' it may bias the whole distribution by means of its 'excessive' contribution to it. This possibility has been assessed by a rerun of the correspondence analysis treating 'distant' as a supplementary category. The result of this analysis is a map which resembles the original one very closely (in fact with inertia at $79 \%$ for the first two dimensions), and therefore suggests that the dimensions proposed initially can be considered robust and not excessively influenced by this one item. 
22. This is one of the discriminating criteria proposed by Minami Fujio for the description of polite meanings (cf. Pizziconi 2004: 299, "Consideration"). This refers to the fact that the use of polite forms invariably and inevitably conveys the Speaker's concern or consideration toward a certain object, be that the Speaker him/herself, or the various types of relationship that obtain between a Speaker and others: Addressee(s), Referent(s).

23. see note 14 .

24. Cf. Haugh's observation that a similarity can be observed between English and Japanese conceptualizations of politeness as involving other-oriented aspects (i.e., that one thinks well of others) as well as self-oriented aspects (i. e., that one does not think too highly of oneself) (2004: 105). While the bracketed statements cannot be confirmed by my observations, the others seem to indicate that the double function of politeness markers is a salient psychological distinction.

\section{References}

Arundale, Robert (2006). Face as relational and interactional: A communication framework for research on face, facework, and politeness. Journal of Politeness Research 2 (2): 193-216.

Bourdieu, Pierre (1991). Language and Symbolic Power. Cambridge: Polity Press.

Brown, Penelope and Stephen Levinson (1987 [1978]). Politeness: Some universals in language usage. Cambridge: Cambridge University Press.

Cook, Haruko Minegishi (2005). Reanalysis of discernment from a social constructivist perspective: Academic consultation sessions in Japanese universities (Research Note \#42). Honolulu: University of Hawaii, National Foreign Language Resource Center. http://nflrc.hawaii.edu/NetWorks/NW42.pdf.

Doi, Takeo (1981). Anatomy of Dependence. Tokyo: Kodansha

Eelen, Gino (2001). A Critique of Politeness Theories. Manchester, UK: St Jerome.

Goodwin, Charles and Alessandro Duranti (1992). Rethinking context: An introduction. In Rethinking Context: Language as an Interactive Phenomenon, Alessandro Duranti and Charles Goodwin (eds.), Cambridge: Cambridge University Press.

Hasan, Ruqaiya (1996). Ways of Saying: Ways of Meaning

Haugh, Michael (2004). Revisiting the conceptualisation of politeness in English and Japanese. Multilingua 23 (1/2): 85-109.

Hiraga, Masako K. (1999). DEFERENCE as DISTANCE: Metaphorical Base of Honorific Verb Construction in Japanese. In Cultural, Psychological and Typological Issues in Cognitive Linguistics: Selected Papers of the Bi-annual ICLA Meeting in Albuquerque, July 1995, Masako K. Hiraga, Chris Sinha, and Sherman Wilcox (eds.), 47-68. Amsterdam: John Benjamins.

House, Juliane (2005). Politeness in Germany: Politeness in Germany? In Politeness in Europe, Leo Hickey and Miranda Stewart (eds.), 13-28. Clevedon: Multilingual Matters.

Ide, Sachiko (1989). Formal forms and discernment: Two neglected aspects of linguistic politeness. Multilingua 8 (2/3): 223-248.

Ide, Sachiko, Beverly Hill, Yukiko M. Carnes, Tsunao Ogino, and Akiko Kawasaki (1992). The concept of politeness: An empirical study of American English and Japanese. In Politeness in Language: Studies in its History, Theory and Practice, Richard J. Watts, Sachiko Ide, and Richard Ehlich (eds.), 299-323. Berlin/New York: Mouton de Gruyter.

Ide, Sachiko and Yoshida Megumi (1999). Sociolinguistics, honorifics and gender differences. In The Handbook of Japanese Linguistics, Natsuko Tsujimura (ed), 444480. Oxford: Blackwell. 
Moore, Carmella C., Kimball A. Romney, Ti-Lien Hsia, and Craig D. Rusch (1999). The universality of the semantic structure of emotion terms: Methods for the study of inter- and intra-cultural variability. American Anthropologist 101 (3): 529-546.

Obana, Yasuko and Takako Tomoda (1994). The sociological significance of "politeness" in English and Japanese languages. Report from a pilot study. Japanese Studies Bulletin 14 (2): 37-49

Osgood, Charles, William H. May, and Murray S. Miron (1975). Cross-cultural Universals of Affective Meaning. Urbana: University of Illinois Press.

Pizziconi, Barbara (2004). Keigo [translation of Minami Fujio's Keigo]. SOAS Working papers in Linguistics 13: 281-311.

Pizziconi, Barbara (2006a). Politeness. In Encyclopaedia of Language and Linguistics, 2nd edition, Keith Brown (ed). Oxford: Elsevier.

Pizziconi, Barbara (2006b). Learning to reframe: Japanese benefactives, metalinguistic beliefs and the identities of L2 users. In Readings in Second Language Pedagogy and Second Language Acquisition in a Japanese Context, Asako Yoshitomi, Tae Umino, and Masashi Negishi (eds), 119-153. Amsterdam: John Benjamins.

Romney, Kimball A., John P. Boyd, Carmella C. Moore, William H. Batchelder, and Timothy J. Brazill (1996). Culture as shared cognitive representations. Proceedings of the National Academy of Science, USA 93: 4699-4705.

Romney, A. K., Carmella C. Moore, and Craig D. Rusch (1997). Cultural universals: Measuring the semantic structure of emotion terms in English and Japanese. Proceedings of the National Academy of Science, USA 94: 5489-5494.

Romney, A. K. and Carmella C. Moore (1998). Toward a theory of culture as shared cognitive structures. Ethos 26 (3): 314-337

Romney, A. K., Carmella C. Moore, William H. Batchelder, and Ti-Lien Hsia (2000). Statistical methods for characterizing similarities and differences between semantic structures. Proceedings of the National Academy of Science, USA 97 (1): 518-523.

Rusch, Craig D. (2004). Cross-cultural variability of the semantic domain of emotion terms: An examination of English Shame and Embarass with Japanese Hazukashii. Cross-cultural research 38 (3): 236-248.

Schutz, Alfred (1973) Collected Papers I. The Problem of Social Reality, M. Natanson (ed.), The Hague: Mouton de Gruyter.

Slobin, Dan. I. (1996). From "thought and language" to "thinking to speaking". In Rethinking Linguistic Relativity, John J. Gumperz and Stephen C. Levinson (eds.), 70-96. Cambridge: Cambridge University Press.

Sperber, Dan (1996). Explaining Culture: A Naturalistic Approach. Blackwell: Oxford.

Terkourafi, Marina (2005). Beyond the micro-level in politeness research, Journal of Politeness Research 1(2): 237-262.

Tulving, Endel (1972). Episodic and semantic memory. In Organization of memory, Endel Tulving and W. Donaldson (eds.), 381-403. New York: Academic Press.

Watts, Richard J. (1992) Linguistic politeness and politic verbal behaviour: Reconsidering claims for universality. In Politeness in Language. Studies in its History, Theory and Practice, Richard J. Watts, Sachiko Ide, and Richard Ehlich.(eds.), 43-70. Berlin/New York: Mouton de Gruyter.

Watts, Richard J. (2003). Politeness. Cambridge: Cambridge University Press.

Wetzel, Patricia (2001). Final vocabulary. In Danwa no Politeness: Discourse Politeness. Tokyo: The National Language Research Institute.

Wierzbicka, Anna (1992). Semantics, Culture and Cognition. Universal Concepts in Culture-Specific Configurations, Oxford: Oxford University Press 


\section{Appendix 1}

Only the English map is reproduced here for economy reasons. The Japanese map had exactly the same format.

\section{FOR SPEAKERS OF BRITISH ENGLISH ONLY}

Please read the pairs below and evaluate how similar the meanings of the two words are.

Tick the circle corresponding to the grade of similarity $(5=$ very similar; $1=$ very different).

for example:

\begin{tabular}{|l|l|l|l|l|l|l|}
\cline { 3 - 7 } \multicolumn{2}{l|}{} & 5 & 4 & 3 & 2 & 1 \\
\hline big & large & & $\mathrm{x}$ & & & \\
\hline big & narrow & & & & & $\mathrm{x}$ \\
\hline
\end{tabular}

$\begin{array}{ll}\text { polite } & \text { appropriate } \\ \text { polite } & \text { nice } \\ \text { polite } & \text { considerate } \\ \text { polite } & \text { courteous } \\ \text { polite } & \text { distant } \\ \text { polite } & \text { kind } \\ \text { polite } & \text { friendly } \\ \text { polite } & \text { well-mannered } \\ \text { polite } & \text { educated } \\ \text { appropriate } & \text { nice } \\ \text { appropriate } & \text { considerate } \\ \text { appropriate } & \text { courteous } \\ \text { appropriate } & \text { distant } \\ \text { appropriate } & \text { kind } \\ \text { appropriate } & \text { friendly } \\ \text { appropriate } & \text { well-mannered } \\ \text { appropriate } & \text { educated } \\ \text { nice } & \text { considerate } \\ \text { nice } & \text { courteous } \\ \text { nice } & \text { distant } \\ \text { nice } & \text { kind } \\ \text { nice } & \text { friendly } \\ \text { nice } & \text { well-mannered } \\ \text { nice } & \text { educated } \\ \text { considerate } & \text { courteous }\end{array}$

\begin{tabular}{|l|l|l|l|l|}
\hline 5 & 4 & 3 & 2 & 1 \\
\hline & & & & \\
\hline & & & & \\
\hline & & & & \\
\hline & & & & \\
\hline & & & & \\
\hline & & & & \\
\hline & & & & \\
\hline & & & & \\
\hline & & & & \\
\hline & & & & \\
\hline & & & & \\
\hline & & & & \\
\hline & & & & \\
\hline & & & & \\
\hline & & & & \\
\hline & & & & \\
\hline & & & & \\
\hline & & & & \\
\hline & & & & \\
\hline & & & & \\
\hline & & & & \\
\hline & & & & \\
\hline & & & & \\
\hline & & & & \\
\hline & & & & \\
\hline
\end{tabular}




$\begin{array}{ll}\text { considerate } & \text { distant } \\ \text { considerate } & \text { kind } \\ \text { considerate } & \text { friendly } \\ \text { considerate } & \text { well-mannered } \\ \text { considerate } & \text { educated } \\ \text { courteous } & \text { distant } \\ \text { courteous } & \text { kind } \\ \text { courteous } & \text { friendly } \\ \text { courteous } & \text { well-mannered } \\ \text { courteous } & \text { educated } \\ \text { distant } & \text { kind } \\ \text { distant } & \text { friendly } \\ \text { distant } & \text { well-mannered } \\ \text { distant } & \text { educated } \\ \text { kind } & \text { friendly } \\ \text { kind } & \text { well-mannered } \\ \text { kind } & \text { educated } \\ \text { friendly } & \text { well-mannered } \\ \text { friendly } & \text { educated } \\ \text { well-mannered } & \text { educated }\end{array}$

\begin{tabular}{|l|l|l|l|l|}
\hline & & & & \\
\hline & & & & \\
\hline & & & & \\
\hline & & & & \\
\hline & & & & \\
\hline & & & & \\
\hline & & & & \\
\hline & & & & \\
\hline & & & & \\
\hline & & & & \\
\hline & & & & \\
\hline & & & & \\
\hline & & & & \\
\hline & & & & \\
\hline & & & & \\
\hline & & & & \\
\hline & & & & \\
\hline & & & & \\
\hline & & & & \\
\hline
\end{tabular}

Please provide the following data as well, by ticking the appropriate box:

\begin{tabular}{|c|c|c|c|c|}
\hline Gender & male & & female & \\
\hline Age & $18-29$ & $30-39$ & $40-49$ & $\begin{array}{l}50 \text { and } \\
\text { above }\end{array}$ \\
\hline $\begin{array}{l}\text { Have you lived abroad } \\
\text { for more than } 1 \text { year? }\end{array}$ & Yes & No & & \\
\hline If so, for how long? & $1-2$ & $2-5$ & $5-10$ & $\begin{array}{l}10 \text { and } \\
\text { above }\end{array}$ \\
\hline
\end{tabular}


238 Barbara Pizziconi

Appendix 2

\begin{tabular}{ll|rr|rr}
\hline & & \multicolumn{2}{|l|}{$\begin{array}{l}\text { English } \\
\text { speakers }\end{array}$} & & \multicolumn{2}{l}{$\begin{array}{l}\text { Japanese } \\
\text { speakers }\end{array}$} \\
\hline Gender & Male & 56 & 63.64 & 57 & 36.54 \\
& Female & 32 & 36.36 & 99 & 63.46 \\
& & 88 & 100.00 & 156 & 100.00 \\
\hline Age & $18-29$ & 30 & 34.09 & 29 & 18.59 \\
& $30-39$ & 26 & 29.55 & 57 & 36.54 \\
& $40-49$ & 6 & 6.82 & 37 & 23.72 \\
& 50 and above & 26 & 29.55 & 33 & 21.15 \\
& & 88 & 100.00 & 156 & 100.00 \\
\hline Have you lived & No & 58 & 65.91 & 65 & 41.67 \\
abroad for more & $1-2$ years & 4 & 4.55 & 19 & 12.18 \\
than 1 year & $2-5$ years & 11 & 12.50 & 31 & 19.87 \\
& $5-10$ years & 9 & 10.23 & 19 & 12.18 \\
& More than 10 years & 6 & 6.82 & 22 & 14.10 \\
& & 88 & 100.00 & 156 & 100.00 \\
\hline
\end{tabular}




\section{Appendix 3}

Table 1: Summary of similarity rating by English monolingual speakers.

\begin{tabular}{|c|c|c|c|c|}
\hline & & Mean & $\begin{array}{l}\text { Standard } \\
\text { deviation }\end{array}$ & $\begin{array}{l}\text { No of } \\
\text { Observations }\end{array}$ \\
\hline \multirow[t]{9}{*}{ Polite } & appropriate & 2.455 & 1.186 & 88 \\
\hline & nice & 2.818 & 1.006 & 88 \\
\hline & considerate & 3.557 & 0.851 & 88 \\
\hline & courteous & 4.489 & 0.707 & 88 \\
\hline & distant & 1.591 & 0.834 & 88 \\
\hline & kind & 2.568 & 0.939 & 88 \\
\hline & friendly & 2.750 & 0.932 & 88 \\
\hline & well-mannered & 4.670 & 0.598 & 88 \\
\hline & educated & 2.170 & 1.014 & 88 \\
\hline \multirow[t]{8}{*}{ appropriate } & nice & 1.750 & 0.944 & 88 \\
\hline & considerate & 2.148 & 1.230 & 88 \\
\hline & courteous & 2.159 & 1.127 & 88 \\
\hline & distant & 1.466 & 0.916 & 88 \\
\hline & kind & 1.705 & 0.931 & 88 \\
\hline & friendly & 1.705 & 0.907 & 88 \\
\hline & well-mannered & 2.273 & 1.312 & 88 \\
\hline & educated & 1.830 & 1.047 & 88 \\
\hline \multirow[t]{7}{*}{ nice } & considerate & 3.273 & 0.962 & 88 \\
\hline & courteous & 3.170 & 0.980 & 88 \\
\hline & distant & 1.250 & 0.608 & 88 \\
\hline & kind & 3.864 & 0.894 & 88 \\
\hline & friendly & 3.830 & 0.980 & 88 \\
\hline & well-mannered & 3.330 & 0.974 & 88 \\
\hline & educated & 1.750 & 0.869 & 88 \\
\hline \multirow[t]{6}{*}{ considerate } & courteous & 3.693 & 0.909 & 88 \\
\hline & distant & 1.307 & 0.646 & 88 \\
\hline & kind & 3.955 & 0.782 & 88 \\
\hline & friendly & 3.148 & 0.805 & 88 \\
\hline & well-mannered & 3.386 & 0.910 & 88 \\
\hline & educated & 1.852 & 0.983 & 88 \\
\hline \multirow[t]{5}{*}{ courteous } & distant & 1.455 & 0.824 & 88 \\
\hline & kind & 2.955 & 0.838 & 88 \\
\hline & friendly & 2.852 & 0.873 & 88 \\
\hline & well-mannered & 4.364 & 0.868 & 88 \\
\hline & educated & 1.955 & 0.988 & 88 \\
\hline \multirow[t]{4}{*}{ distant } & kind & 1.170 & 0.527 & 88 \\
\hline & friendly & 1.114 & 0.487 & 88 \\
\hline & well-mannered & 1.443 & 0.796 & 88 \\
\hline & educated & 1.352 & 0.739 & 88 \\
\hline \multirow[t]{3}{*}{ kind } & friendly & 3.591 & 0.874 & 88 \\
\hline & well-mannered & 2.807 & 0.952 & 88 \\
\hline & educated & 1.523 & 0.797 & 88 \\
\hline \multirow[t]{2}{*}{ friendly } & well-mannered & 2.409 & 0.961 & 88 \\
\hline & educated & 1.455 & 0.722 & 88 \\
\hline well-mannered & educated & 2.068 & 1.136 & 88 \\
\hline
\end{tabular}


Table 2: Summary of similarity rating by Japanese monolingual speakers

\begin{tabular}{|c|c|c|c|c|}
\hline & & Mean & $\begin{array}{l}\text { Standard } \\
\text { deviation }\end{array}$ & $\begin{array}{l}\text { No of } \\
\text { Observations }\end{array}$ \\
\hline \multirow{11}{*}{$\begin{array}{l}\text { 礼儀正しい } \\
\text { reigitadashii }\end{array}$} & 丁寧な & 3.692 & 0.951 & 156 \\
\hline & teineina & & & \\
\hline & $\begin{array}{l}\text { 思いやりのある } \\
\text { omoiyarinoaru }\end{array}$ & 2.282 & 0.979 & 156 \\
\hline & $\begin{array}{l}\text { 誠実な } \\
\text { seijitsuna }\end{array}$ & 2.577 & 1.080 & 156 \\
\hline & $\begin{array}{l}\text { 親切な } \\
\text { shinsetsuna }\end{array}$ & 2.276 & 0.944 & 156 \\
\hline & 謙虚な & 2.917 & 1.086 & 156 \\
\hline & kenkyona & & & \\
\hline & $\begin{array}{l}\text { 上品な } \\
\text { joohinna }\end{array}$ & 3.013 & 1.143 & 156 \\
\hline & へりくだる & 2.705 & 1.128 & 156 \\
\hline & $\begin{array}{l}\text { herikudaru } \\
\text { わきまえる } \\
\text { wakimaeru }\end{array}$ & 3.705 & 0.989 & 156 \\
\hline & $\begin{array}{l}\text { 遠慮がちな } \\
\text { enryogachina }\end{array}$ & 2.295 & 1.033 & 156 \\
\hline \multirow{10}{*}{$\begin{array}{l}\text { 丁寧な } \\
\text { teineina }\end{array}$} & 思いやりのある & 2.622 & 1.100 & 156 \\
\hline & omoiyarinoaru & & & \\
\hline & $\begin{array}{l}\text { 誠実な } \\
\text { seijitsuna }\end{array}$ & 2.724 & 1.095 & 156 \\
\hline & $\begin{array}{l}\text { 親切な } \\
\text { shinsetsuna }\end{array}$ & 2.718 & 1.137 & 156 \\
\hline & 謙虚な & 2.397 & 1.072 & 156 \\
\hline & kenkyona & & & \\
\hline & $\begin{array}{l}\text { 上品な } \\
\text { joohinna }\end{array}$ & 2.750 & 1.136 & 156 \\
\hline & ヘりくだる & 2.231 & 1.018 & 156 \\
\hline & $\begin{array}{l}\text { herikudaru } \\
\text { わきまえる } \\
\text { wakimaeru }\end{array}$ & 2.481 & 1.095 & 156 \\
\hline & $\begin{array}{l}\text { 遠慮がちな } \\
\text { enryogachina }\end{array}$ & 2.109 & 0.931 & 156 \\
\hline \multirow{7}{*}{$\begin{array}{l}\text { 思いやりのある } \\
\text { omoiyarinoaru }\end{array}$} & 誠実な & 3.359 & 1.097 & 156 \\
\hline & 親切な & 4.186 & 0.853 & 156 \\
\hline & $\begin{array}{l}\text { shinsetsuna } \\
\text { 謙虚な }\end{array}$ & 2.288 & 0.884 & 156 \\
\hline & kenkyona & & & \\
\hline & $\begin{array}{l}\text { 上品な } \\
\text { joohinna }\end{array}$ & 1.795 & 0.830 & 156 \\
\hline & へりくだる & 1.590 & 0.678 & 156 \\
\hline & $\begin{array}{l}\text { herikudaru } \\
\text { わきまえる } \\
\text { wakimaeru }\end{array}$ & 2.141 & 0.977 & 156 \\
\hline
\end{tabular}


(Table 2: continued)

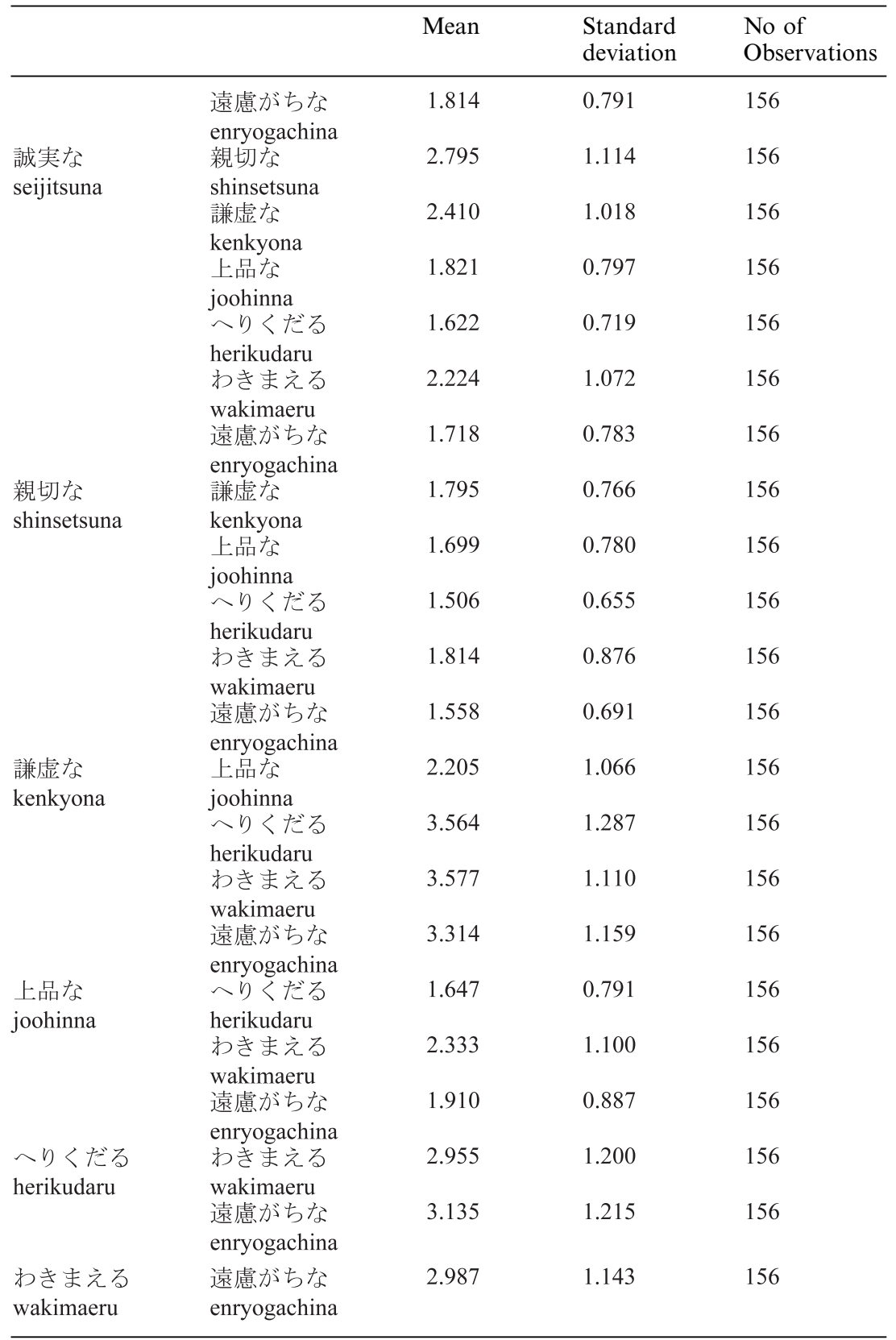

